\title{
The Effect of the Electrical Stimulation on Temperature Rise in the Retinal Tissue for Visual Prostheses
}

\author{
Mahmut Emin Çelik and İrfan Karagöz
}

\begin{abstract}
Visual perception which is one of the most valuable perceptions for human beings may be lost over time because of various diseases such as Age Related Macular Degeneration (AMD) and Retinitis Pigmentosa (RP). These degenerative diseases cause severe damage to the certain parts of visual pathway and irreversible blindness. For the past last decades, with the improvements in the areas such as microelectronics, neuroscience and bioengineering, researches conducting on design and implementation of visual prosthetics become a promising therapeutic approach for the visual restoration. Visual perception, called phosphene, is reported to be obtained in studies which are based on electrical stimulation of the intact parts of the visual pathway. There are major factors that have to be considered in the design stage of a visual prosthesis system. One of them is the temperature change of the targeted retinal tissue and its surrounding due to electrical stimulation. In this study, a model is created to investigate thermal influence of an implant placed internal surface of the retinal tissue and solution is made using finite element analysis. It is shown that the temperature rise has highest value near the stimulation electrode and its surroundings in the case of using the model with thermal insulation. When the heat transfer mechanism is added to the simulation model, it is seen that the temperature rise is less and looks more realistic. With additive effect of heat transfer to the surrounding tissue and distance from stimulation electrode, temperature decreases away from the stimulation electrode.
\end{abstract}

Index Terms-Electrical stimulation, finite element analysis, temperature change, visual prosthesis.

\section{INTRODUCTION}

Nowadays, over 40 million people lost their visual perception due to the diseases related with the retinal degeneration [1]. Degenerative retinal diseases that result in the most prevalent blindness are Retinitis Pigmentosa (RP) and Age Related Macular Degeneration (AMD) [2]. Degenerative retinal diseases that lead to the most prevalent blindness are AMD and RP throughout the world and unfortunately there is no effective treatment method ranging from rebirth of photoreceptors from stem cells to neuro-protective therapy [3], [4]. Retinal Pigment Epithelium (RPE) layer of the retina are damaged by AMD. $30 \%$ of the population over 70 years old is affected by this damage in AMD's early phases, and this leads to tunnel like vision prior to total blindness. RP impairs the photoreceptor layer [5], [6]. It is reported that more than 40 million of patients are affected by blindness all over the world, and more than 4 million of

Manuscript received January 21, 2014; revised April 10, 2014.

M. E. Çelik and I. Karagöz are with the Department of Electrical-Electronics Engineering, Gazi University, Ankara, Turkey (e-mail: mahmutemincelik@gazi.edu.tr, irfankaragoz@gazi.edu.tr). people in USA will have suffered from AMD by the year 2020 [7]. There is not any research which has been performed yet on the cause effect of blindness in Turkey, however it is reported in [8] that main reason about $30 \%$ of the cases with patients are related with these two diseases.

Although photoreceptor layer is lost because of the diseases, certain parts of the visual pathway remain intact [3], [9]. \%70's of retinal ganglion cells (RGCs) and visual cortex in the brain maintain their functionality even with severely advanced diseases [10]. Visual perception can be regenerated by electrically stimulating these remaining nerve cells of the retina to provide functional vision to patients. The recent developments in neuroscience, bioengineering, micro-technology have led to the innovation of sophisticated microelectronic devices designed to stimulate the appropriate nerve tissues to provide the functionality in a certain level [11].

Thought of electrical stimulation of visual pathway is not new and dates back to 1970 s [12]. The main principle underlying a visual prosthesis system is to elicit visual perception with electrical stimulation of the remaining nerve cells without using the impaired layers in visual pathway. There are extraocular and intraocular parts of a visual prosthesis system. While an electrode array and necessary electronics are placed to the intraocular region, a miniature camera, supply electronics and some electronic units are outside of the eye. Visual prosthesis may be named according to anatomical location of the targeted tissue to stimulate such as retinal, cortical and optic nerve prosthesis, as shown Fig. 1 [6].

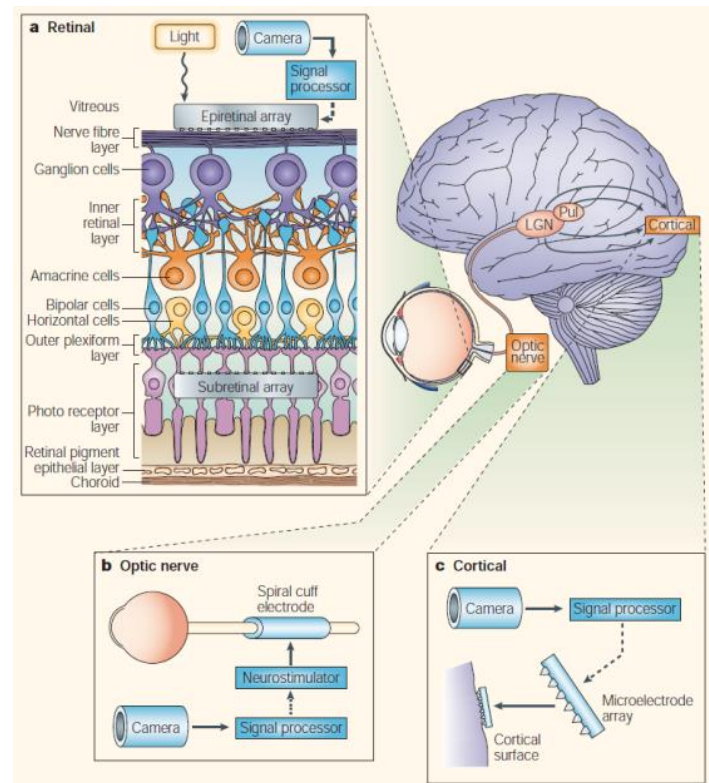

Fig. 1. Anatomical locations of visual prosthesis [11]. 
There are some physical, electrical and biological constraints that should be taken into consideration for an efficient visual prosthesis which will be used long term. Understanding physiological structure of eye, materials and procedures to be used have great importance in design phase of a visual prosthesis. Simulation models are powerful tool and used to understand how a visual prosthesis is designed properly, and which parameter affects the performance of the system crucially before it is fabricated.

Development of realistic simulation models provides great benefits. The implant, a microelectrode array (MEA), which will be placed to the retinal tissue is a source of heat because of power dissipation. This heat leads to temperature change around the MEA, and it has to be within allowable limits to avoid thermal damage to the tissues. Simulation models are useful to test whether the system are within these limits, or not Thus, the system can be revised if necessary. In this study, thermal effect of the stimulation electrodes on targeted tissue and its surroundings is investigated. Firstly, stimulation electrode and retinal tissue are modeled under two different mode, namely thermal insulation and heat transfer mechanism as shown in Fig. 2. Then, parameters which are required for heat transfer are assigned. The model is solved using Finite Element Analysis (FEA) to examine temperature change in retinal tissue.

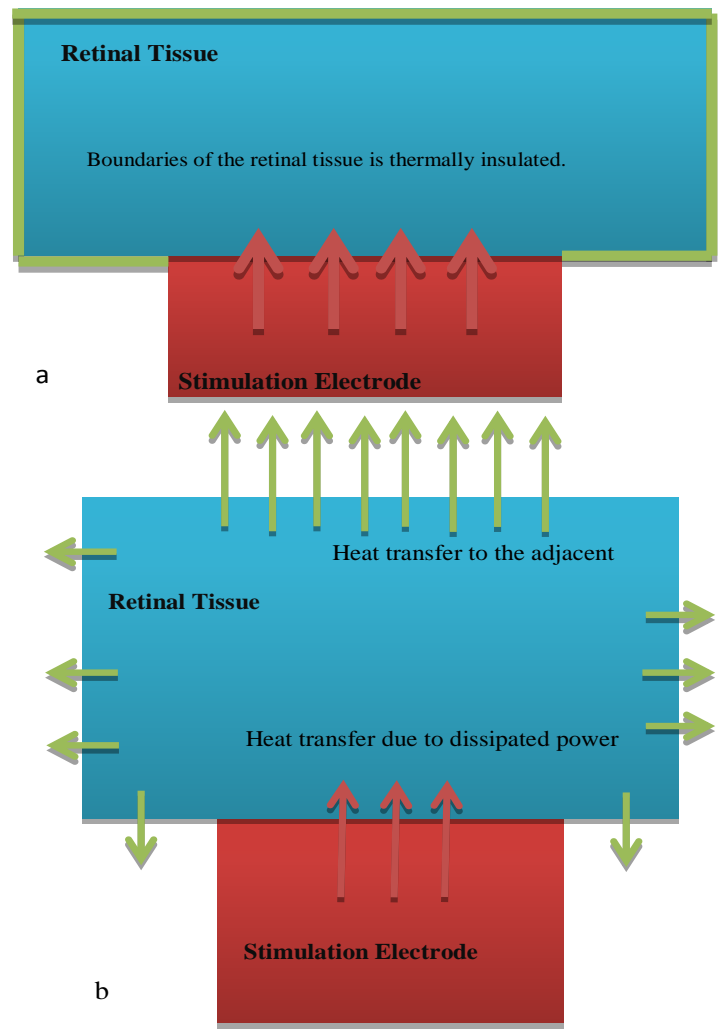

Fig. 2. Schematic representation of developed electrode and tissue model in 2-D, (a) Thermally insulated model, (b) The model using heat transfer mechanism.

\section{THE EFFECT OF TEMPERATURE RISE IN TISSUES}

Heat increase due to electrical stimulation of the tissue is categorized into two main sections, namely Joule heat and metabolic reactions [13], [14]. Joule heat forms in the presence of electric field. Temperature change depends on tissue properties and stimulation parameters such as amplitude, frequency, pulse width, monophasic or biphasic stimulation. High temperature change to be taken place in the nerve cells of the retinal tissue which is quite sensitive to heat affects adversely membrane properties, like voltage-controlled channels which are related with the temperature, and neural network. Moreover, this can lead to cell deaths [15]-[17].

It is reported that increase of $3^{\circ} \mathrm{C}$ more than normal body temperature can lead to various physiological abnormalities [18]. Additionally, it is shown that body temperature increment of $2^{\circ} \mathrm{C}$ and $3{ }^{\circ} \mathrm{C}$ has an impact upon a number of defects in tests conducted using guinea pig, rat [19], [20]. On the other hand, it is quite risky in terms of usage that the implants which are placed to the retina and stay there through long-term induce high temperature change. To investigate temperature side-effects of the neuroprosthetic devices has a critical role for a stable system in the design phase of the research. So, examining these effects is both necessary and useful.

\section{DETERMinAtion OF THE TEMPERATURE RISE IN THE CAUSE OF ElECTRICAL STIMULATION USING SimULATION MODEL}

In consideration of the mentioned aspects, a model representing retinal tissue and stimulation electrode is created. The retinal tissue is considered to be one layer structure, besides it is realistically modeled that it can deliver the heat either within the retinal tissue or every direction like real heat transfer mechanism of the live tissue, as shown Fig. 2. Temperature change is examined in the base of $12 \mathrm{~mW}$ power dissipation implant with 60 electrodes [21], [22]. The body temperature is initially assumed as $36^{\circ} \mathrm{C}$. Finite Element Analysis is used to simulate heat transfer from stimulation electrode to targeted retinal tissue surroundings.

It is assumed that the tissue is homogeneous and isotropic, and heat transfer is examined under stationary condition. Heat transfer is based on Pennes bioheat equation by (1).

$$
\nabla \times(-k \nabla T)=\rho_{b} C_{b} \omega_{b}\left(T_{b}-T\right)+Q_{m e t}+Q_{e x t}
$$

Thermal insulation is a boundary condition and means that the domain is insulated, that is, heat cannot pass from one side to another, (2).

$$
n \times(k \nabla T)=0
$$

where $k, \rho_{b}, C_{b}, \omega_{b}, Q_{m e t}, Q_{e x t} \quad$ represent thermal conductivity $(\mathrm{W} / \mathrm{mK})$, density $\left(\mathrm{kg} / \mathrm{m}^{3}\right)$, specific heat capacity which is the amount of energy to produce change of a unit temperature $(\mathrm{J} / \mathrm{kg} . \mathrm{K})$, perfusion rate which shows volume of blood per second flowing through a unit volume of tissue $(1 / \mathrm{s})$, heat source of metabolism and external heat source $\left(\mathrm{W} / \mathrm{m}^{3}\right)$ respectively.

Thermal properties of biomaterials such as retina, choroid differ greatly depending on measurement conditions [23]-[26]. 
Parameters used in this study are obtained certain literatures [27], [28], and given in Table I.

\begin{tabular}{|c|c|}
\hline Parameter & Value (Unit) \\
\hline Initial temperature & $\left({ }^{\circ} \mathrm{C}\right)$ \\
\hline Thermal conductivity & $0.528(\mathrm{~W} / \mathrm{mK})$ \\
\hline Density & $1040\left(\mathrm{~kg} / \mathrm{m}^{3}\right)$ \\
\hline Heat capacity & $3650 \quad(\mathrm{~J} /(\mathrm{kgK})$ \\
\hline
\end{tabular}

When the effect of an implant system, which is assumed to be placed inner surface of the retina and has $12 \mathrm{~mW}$ power dissipation, on temperature change across the tissue is examined. Firstly, the model with thermal insulation is simulated. It is assumed that boundaries of the retinal tissue are thermally insulated. Induced temperature rise in tissue is $7.92^{\circ} \mathrm{C}$ near the stimulation electrodes, heat source, Fig. 3(a). Then, the model with another mode, heat transfer mechanism, is simulated. $2.27^{\circ} \mathrm{C}$ temperature increase is observed as maximum, Fig. 3(b).
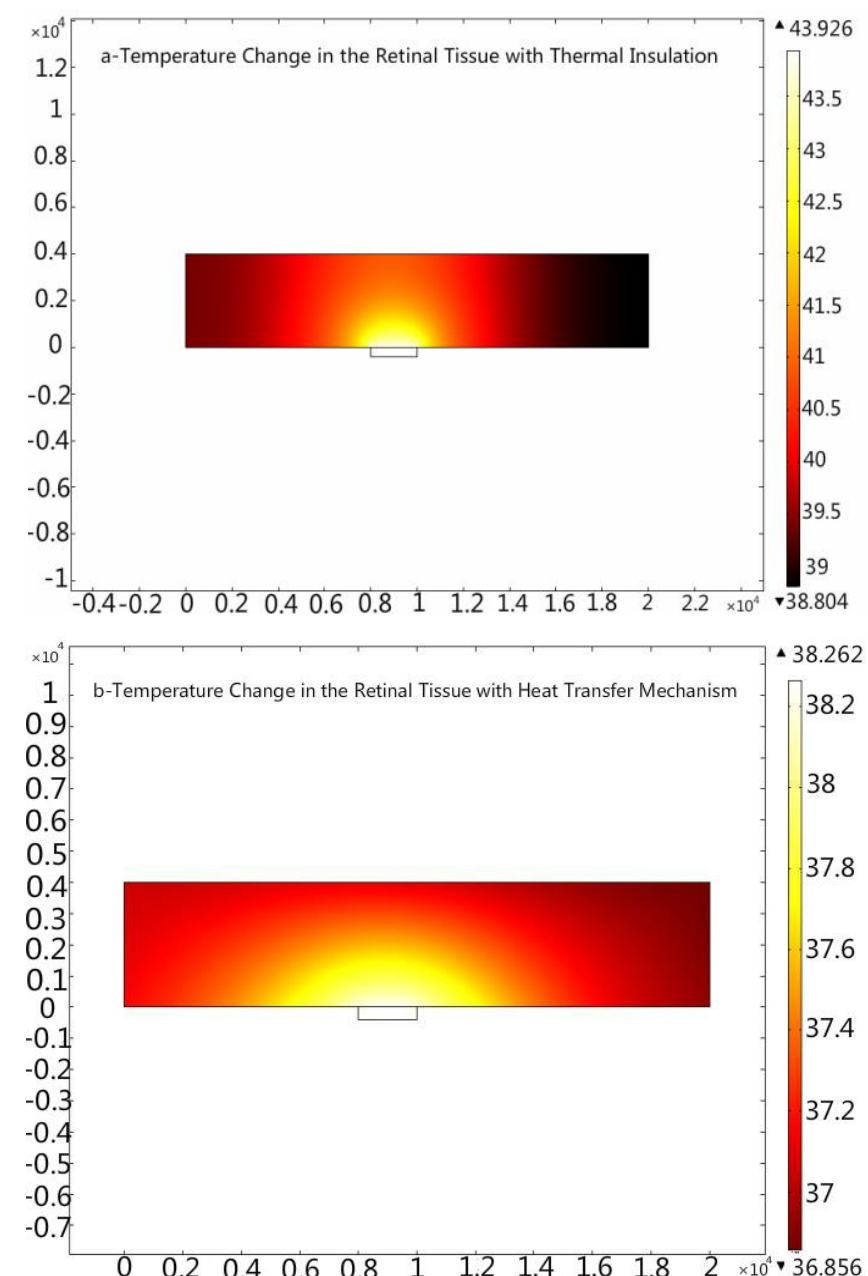

Fig. 3. Temperature Distribution in Retinal Tissue, (a) Thermal Insulation mode, (b) Heat Transfer Mechanism.

It is seen that the position where the maximal increase in the temperature is nearest surrounding tissue to be stimulated by stimulation electrodes. Furthermore, as it is moved from the stimulation electrodes, it is seen that temperature rise decreases. When two different modes are compared, the model with heat transfer mechanism is more realistic. Scattering the heat to the neighbor regions in every directions help the temperature disperse and total rise remain on a level with $2.27^{\circ} \mathrm{C}$. Thermal insulation keeps the energy within the boundaries selected, so increase in the temperature becomes much more. These results comply with the literature.

\section{CONCLUSION}

Recently, development of a visual prosthesis system has gained enormous interest. It is reported in literature that visual perception, called phosphene, can be obtained using electrical stimulation of remaining nerve cells through visual pathway. There are a number of physiological and biological causes that should be taken into consideration. Researches using realistic simulation models save both time and unnecessary expenses. In this point, simulation studies have a critical importance.

Temperature rise in the tissue because of the implant dissipating power is investigated using developed retinal model. The model is simulated under two different modes. With this model, it is observed that the temperature increases $7.92^{\circ} \mathrm{C}$ and $2.27^{\circ} \mathrm{C}$ for $12 \mathrm{~mW}$ power dissipation implant system with the modes of thermal insulation and heat transfer mechanism respectively. The difference emerges from the concepts the simulation used, that is, in contrast to thermal insulation mode, heat transfer mechanism provides an advantage to scatter the heat in every direction across the retinal tissue as it really does. Additionally, the highest temperature change takes place near the electrode array where the electrical stimulation is applied. When it is moved forum source of heat, which is stimulation electrodes of implant system, the increment in temperature diminishes. These results support with the literature.

This study which simulates thermal change on the stimulated retinal tissue forms a basis for more realistic simulation models which will include capacitive effects and time dependence, so it will be understood how electrical and geometrical parameters affect the performance of whole system.

\section{REFERENCES}

[1] R. J. Greenberg, T. J. Velte, M. S. Humayun, G. N. Scarlatis, and E. A. Jr de Juan, "A computational model of electrical stimulation on the retinal ganglion cell," IEEE Trans. Biomedical Engineering, vol. 46, pp. 505-514, 1999.

[2] N. P. Cottaris and S. D. Elfar, "How the retinal network reacts to epiretinal stimulation to form the prosthetic visual input to the cortex," Journal of Neural Engineering, vol. 2, pp. S74 -S90, 2005.

[3] J. D. Weiland, W. Liu, and M. S. Humayun, "Retinal prosthesis," Annu. ReV. Biomed. Eng., vol. 7, p. 361, 2005.

[4] R. J. Jensen, O. R. Ziv, and J. F. Rizzo, "Responses of rabbit retinal ganglion cells to electrical stimulation with an epiretinal electrode," $J$. Neural Engineer, vol. 2, p. S16, 2005a.

[5] S. K. Kelly, D. B. Shire, J. Chen, P. Doyle, M. D. Gingerich, W. A Drohan, L. S. Theogarajan, S. F. Cogan, J. L. Wyatt and J. F. Rizzo, "The Boston retinal prosthesis: a 15-channel hermetic wireless neural stimulator," presented at IEEE ISABEL Conference, 2009.

[6] G. Dagnelie, "Retinal implants: emergence of a multidisciplinary field," Current Opinion in Neurology, vol. 25, pp. 67-75, 2012.

[7] L. Theogarajan, "Strategies for restoring vision to the blind: current and emerging technologies," Neuroscience Letters, vol. 519, issue 2, pp. 129-133, 2012.

[8] K. Iniewski, Integrated Microsystems Electronics, Photonics, and Biotechnology, CRC Press, ch. 9, 2011.

[9] E. Zrenner, "Will retinal implants restore vision?" Science, vol. 295, pp. 1022-1025, 2002. 
[10] G. Chader, J. Weiland, and M. S. Humayun, "Artificial vision: needs, functioning, and testing of a retinal electronic prosthesis," Progress in Brain Research, vol. 175, pp. 317-332, 2009.

[11] L. B. Merabet, J. F. Rizzo, A. Amedi, D. C. Somers, and A. Pascual-Leone, "What blindness can tell us about seeing again: merging neuroplasticity and neuroprostheses," Nat Rev., vol. 6, pp. 71-77, 2005.

[12] G. S. Brindley and W. S. Lewin, "The sensations produced by electrical stimulation of the visual cortex," J. Physiol., vol. 196, pp. 479-493, 1968.

[13] I. Chang, "Finite element analysis of hepatic radiofrequency ablation probes using temperature-dependent electrical conductivity," Biomed. Eng. Online, pp. 2-12, 2003.

[14] S. Tungjitusolmun, E. J. Woo, and H. Cao, "Finite element analyses of uniform current density electrodes for radio-frequency cardiac ablation," IEEE Trans. Biomed. Eng., vol. 47, pp. 32-40, 2000.

[15] B. Bennetts, M. L. Roberts, A. H. Bretag, and G. Y. Rychkov, "Temperature dependence of human muscle ClC-1 chloride channel," J. Physiol., vol. 535, pp. 83-93, 2001.

[16] S. Fujii, H. Sasaki, K. Ito, K. Kaneko, and H. Kato, "Temperature dependence of synaptic responses in guinea pig hippocampal CA1 neurons in vitro," Cell Mol. Neurobiol., pp. 379-391, 2002.

[17] M. M. Elwassif, Q. Kong, M. Vazquez, and M. Bikson, "Bio-heat transfer model of deep brain stimulation-induced temperature changes," J. Neural Eng., vol. 3, pp. 306-315, 2006.

[18] T. M. Seese, H. Harasaki, G. M. Saidel, and C. R. Davies, "Characterization of tissue morphology, angiogenesis, and temperature in the adaptive response of muscle tissue in chronic heating," Lab. Investigation, vol. 78, pp. 1553-1562, 1998.

[19] M. Ueda, J. Bures, and J. Fischer, "Spreading depression elicited by thermal effects of ultrasonic irradiation of cerebral cortex in rats," $J$. Neurobiol., vol. 8, pp. 381-393, 1977.

[20] T. Fujii and Y. Ibata, "Effects of heating on electrical activities of guinea pig olfactory cortical slices," Eur. J. Physiol., vol. 392, pp. 257-260, 1982.

[21] K. Gosalia, J. Weiland, M. Humayun, and G. Lazzi, "Thermal elevation in the human eye and head due to the operation of a retinal prosthesis," IEEE Trans. Biomed. Eng., vol. 51, no. 8, pp. 1469-1477, 2004.

[22] G. Lazzi, "Thermal effects of bioimplants," IEEE Eng. Med. Biol. Mag., vol. 24, no. 5, pp. 75-81, 2005.
[23] H. F. Bowman, E. G. Cravalho, and M. Woods, "Theory, measurement and application of thermal properties of biomaterials," Ann. Rev. Biophys. Bioeng., vol. 4, pp. 48-80, 1975.

[24] F. A. Duck, Physical Properties of Tissues: A Comprehensive Reference Book, San Diego, CA: Academic, 1990.

[25] H. F. Bowman, "Heat transfer and thermal dosimetery," J. Microwave Power, vol. 16, pp. 121-133, 1981.

[26] S. Kim, P. Tathireddy, R. A. Normann, and F. Solzbacher, "Thermal impact of an active 3-D microelectrode array implanted in the brain," IEEE Trans Neural Syst Rehabil Eng., vol. 15, no. 4, pp. 493-501, 2007.

[27] C. M. Collins, M. B. Smith, and R. Turner, "Model of local temperature changes in brain upon functional activation," J. Appl. Physiol., vol. 97, pp. 2051-2055, 2004.

[28] C. W. Connor and K. Hynynen, "Patterns of thermal deposition in the skull during transcranial focused ultrasound surgery," IEEE Trans. Biomed. Eng., vol. 51, no. 10, pp. 1693-1706, Oct. 2004.

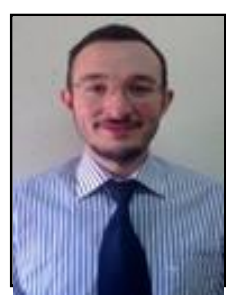

Mahmut Emin Çelik was born in Sakarya in 1987 $\mathrm{He}$ received the B.Sc. and the M.Sc. degrees in electrical-electronics engineering from University of Kırıkkale and Gazi, in 2008 and 2010 respectively. He works at Electrical and Electronics Engineering Department, Gazi University since 2009 as research assistant. Currently, he is a Ph.D. student and his research areas include image processing, modeling and visual prosthesis.

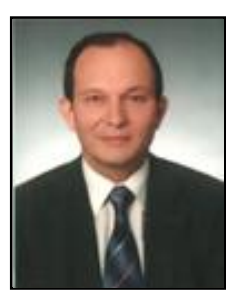

İrfan Karagöz was born in Ankara, Turkey, in 1958. $\mathrm{He}$ received the B.Sc. and M.Sc. degrees in electrical-electronics engineering in 1983 and 1985 from Bogazici University and the Ph.D. degree from Hacettepe University in 1993. Currently, he is a full professor at Electrical Electronics Engineering Department of Gazi University. His research interests include sensorineural implant systems, signal processing and biomedical instrumentation. 